\title{
The Luba Basa Institution: The Challenge on Shinasha Identity
}

\author{
Abebe Ano Alula \\ Department of History and Heritage Management, College of Social Sciences, \\ Wollega University, Post Box No: 44, Gimbi, Ethiopia
}

\begin{tabular}{|c|c|}
\hline Abstract & Article Information \\
\hline \multirow{9}{*}{$\begin{array}{l}\text { The Article deals, among other things with the traditions of origin, } \\
\text { early patterns of expansion and settlements of Shinasha. It also } \\
\text { explores the history and culture of the Shinasha and Oromo } \\
\text { communities in the region of Metekel and their assimilation and } \\
\text { inco-operation of the former by later. The paper aims to contribute } \\
\text { to the understanding of the impact of Luba Basa institution on } \\
\text { people and culture of the Shinasha society. }\end{array}$} & $\begin{array}{l}\text { Article History: } \\
\text { Received : } 16-02-2012\end{array}$ \\
\hline & Revised : 21-05-2012 \\
\hline & Accepted : 10-06-2012 \\
\hline & Keywords: \\
\hline & Shinasha-Oromo \\
\hline & Cultural assimilation \\
\hline & $\begin{array}{l}\text { Luba basa } \\
\text { Metekel }\end{array}$ \\
\hline & $\begin{array}{l}\text { *Corresponding Author: } \\
\text { Abebe Ano Alula }\end{array}$ \\
\hline & E-mail: bebeano2001@yahoo.com \\
\hline
\end{tabular}

\section{INTRODUCTION}

Metekel is a vast territory north of the Abbey River on the Ethio-Sudanese border. It is bounded by Gondar in the north, Wollega and Asossa in the south, Gojjam in the east and Sudan in the west. It forms one of the provinces in Gojjam comprising the districts of Mandura, Debate, Dangur, Gwangwa, Guba, and Wombera. Currently, Metekel is one of the three zones of the national regional state of the Benishangul-Gumz. It maintained its former territories with the exception of Gwangwa and part of Debati, which became part of the Amhara National Regional state as a result of the administrative reform of 1991 (Tsega,2002). Wombera is one of and the largest district in Metekel administrative zone. It is bounded by the districts of Guba and Dangur in the north, Mandura and Dibati in the east, and Wollega in the south and west. The rivers of Beles, Sharp and Abbay form demarcation line between Wombera and the adjacent districts respectively. As to its climatic condition, Dega (highland) accounts for $10 \%$, Woyna Dega (temperate) $50 \%$, while Qolla (low land) $40 \%$. Most of its parts especially the temperate zone are covered by dense forest and thus it is common to find different animal species (Debela, 2000). Peoples of different ethnic affiliations with their own distinct languages, cultural practices and socioeconomic formations inhabit the district. The Gumz, the Shinasha, the Oromo, the Agaw and the Amhara are main inhabitants of the area. These people have had intensive social, cultural and economic interactions (Ibid). Treating cultural and socio-economic interactions of all these people is beyond the scope of this paper. What the paper attempted here is to take a single aspect of earlier interactions between the Shinasha and the Oromo by closely looking at its effects on the identity of the Shinasha. To do so, it is important to highlight the history of both the peoples.

\section{MATERIALS AND METHODS}

Sources: The study is based on primary and secondary sources. The primary sources have been obtained from informants and personal observations.

Methodology of the Study: The data for this study were collected at Bullen, Dibate, Dangur and Wombera Districts in Metekel. The data to this study were collected by qualitative data 
collecting methods. The primary data were collected through interviews with elders of study areas. Although it difficult to confidently to accept oral information as perfect, I carefully checked and counter-checked with secondary sources available different libraries of Addis Ababa University especially in the Institute of Ethiopian studies.

\section{RESULTS AND DISCUSSION}

\section{The Shinasha People}

The Shinasha have been known by different names. Among these Shinasha, Boro, Dangabo and Sinicho can be mentioned. The most widely used term to denote the people is the Shinasha. The term seems to be a non-derogative Amharic designation, derived from shi ena shi which mean thousands and thousands indicating the multitudes of the people who fled to and settled in the north of the Abbey River (Ali, 1991). Sinicho is an Oromo appellation for the same people. According to the tradition collected by Tesema Ta'a in western Wollega, these people strongly resisted the Oromo expansion into the area. It was most probably due to their stiff resistance that the Oromo associate the people with a very hot pepper 'Sinicho' in Oromo language and called them Sinicho (Tessema, 1980).

Dangabo is also an Oromo appellation for the Shinasha people living in the locality of Metekel. The term might have been derived from the name of the locality itself without pejorative meaning where as Boro is the people's self name widely in use since 1991. According to oral tradition and my informants, Boro is believed to be one of their original ancestral fathers and they would like to be called after him (Erike and Starube, 1979). They claim their founding father to be one Shao, who begot Ashinao, Assibo, Boro and Gongo. These descendants of Shao are said to have divided Gojjam among themselves with Ashinao taking Shashino, Assibo taking Assi, Boro occupying Bure and Gongo settling in Gwangwa.

Local Shinasha traditions trace their origin to the land of Canaan from where they were migrated to Egypt because of the lack of pastureland. The same reason combined with starvation and conflict with the local peoples drove the Shinasha out of Egypt in search of fertile and conducive place of settlement. Consequently, following the courses of the Nile River, they migrated to Ethiopia. In the course of their migration, as claimed by their tradition they were led by Nesi and Abuguri. The former was said to have had the knowledge of traditional medicine with which he showed directions to the people while the latter was rich in skill; made Javelins, spears, arrows and shield, and thus offered the people to protect themselves. Meanwhile they entered Ethiopia through the north-west moved and settled in Shewa. But due to over population there, they came to Gojjam and occupied places like Damot, Bureshindy, Shashina, Gumez, Azena, Gumyesu, Zigem and the surroundings (Ali et al.,1991).

In spite of this tradition, available sources do not support the Canaanite origin of the Shinasha. Fleming indicates that large and powerful kingdom called Gonga existed in earlier times prior to the $16^{\text {th }}$ century and this kingdom stretched from southern Gojjam to nearly the southern limits of western highlands. It was weakened and disintegrated in the $16^{\text {th }}$ century as the result of the Oromo expansion in to the southwestern Ethiopia. Consequently, the Gonga kingdom was divided and hence, the southern Gonga cut off from the northern Gonga to which the Shinasha belong (Fleming, 1976). Moreover, the Jesuit missionaries who traveled from Gojjam across the Abbay to Ennarya in 1613-1614, mentioned Shinasha as Gongas and clearly described their presence on both sides of the Abbay (Beckingham and Hunting Ford, 1954). Shinasha's presence to the Abbay further confirmed by Tesema, who described them as one of the early inhabitants of Wollega prior to the occupation of the area by the Oromo (Tesema, 1980). In the same way, Oljira notes that the Shinasha were among the early inhabitants of Horro Guduru. He describes their stiff resistance against the Oromo and states that they were able to put such a bitter and strong resistance presumably because they possessed a fairly developed form of social organization headed by chieftaincies. They also seem to have been relatively populous. In Horro Guduru the Shinasha found in large numbers in Amuru and Jidda districts; in certain localities like Luquma, Wa'al and Jawaja of Amuru and Harro of Jidda. Oral tradition collected by the same person also indicates that some Shinasha moved from Limmu and Jidda districts, crossed the Abbay and settled in Danagab area of Metekel (Olijira, 1976).

Gonga is also described as a language spoken on both sides of the Abbay as far as kafa to the South. It includes Anfillo, Dawaro, Kafa, Mao, Shinasha, Bosha, Yam and Walayita. It may be divided into three groups Southern Gonga, Central Gonga and Northern Gonga. Southern Gonga comprises Kafa, Sheka and Bosha spoken in the Southwestern regions in the vicinity of the Gojeb River. Central Gonga represents Anfillo spoken in western Wollega where as 
Northern Gonga comprises the Shinasha (Fleming, 1976).

There is striking similarity between the Kafa and Shinasha languages (Table 1) as my interview of individuals at study area reveals. Here are some words.

Table 1: Similarity between Kafa and Shinasha languages.

\begin{tabular}{lll}
\hline Kafa & Shinasha & Meaning \\
\hline Ekka & Ekka & One \\
Guta & Gita & Two \\
Keja & Keza & Three \\
Auda & Auda & Four \\
Ucha & Wussa & Five \\
Shiritta & Shiritta & Six \\
Shewaitta & Shewatta & Seven \\
Shimitta & Shimitta & Eight \\
Jetya & Jedhya & Nine \\
Barro & Bara & Front head \\
Misho & Misho & Injera \\
Asho & Asho & Person (man) \\
Gasho & Gasho & Teeth \\
Wano & wazo & Ear \\
Kisho & Kisho & Hand \\
Macho & Macho & Stomach \\
\hline
\end{tabular}

These evidences show that the Shinasha are one of the several peoples of Ethiopian interior speaking Gonga language. They seem to have been part of the Gonga population who once lived on both sides of the Abbey River. However, their local traditions that portray their Canaanite origin and settlement in Shewa may merely indicate their early contact with Christian highland kingdom.
Major political and demographic developments of the $16^{\text {th }}$ century coupled with early Christian raids into the Gumz country (Metekel) presumably dispersed the Shinasha to their present localities. Christian raids to the area with an intention to exploit the Gold; for which the region is known historically; and ensure suzerainty over the people could be date back to the reign of king Yeshaq (1413-1430). Yeshaq was said to have headed campaign in to Gojjam and Metekel in particular (Ali Suleiman, 1991). Moreover, the campaigns to these areas became more intensive with the gradual shift of centre of the Ethiopian state in the region of Lake Tana and Gondar in the seventeenth century. The expansions of the Christian kingdom into the area were to have brought variety of natural resources and slaves under its direct control. These campaigns had affected the Shinasha and other peoples in the region (Tadesse, 1982).

Theses raids, of course, escalated frequency became the regular affairs of kings since the times of Sarse Dingil (1563-1597). The following statement may reveal this fact. "In the 1570 s and 1580s the other targets of Sarse-Dingil's war were various Oromo tribes in the South and Felasha, the Agaw, the Shinasha and the Gumz peoples in Agewmidir, Wagera, Semen Dembiya and Gojjam" (Tsega, 1997).

It seems that these developments forced the Shinasha to move en mass to the west of Dura River to their present localities. On their way they fought and subdued the Gumz some of whom were retreated into the less favorable lowland areas in the region while others continued to live with them in harsh way. The Shinasha thus, occupied places in Metekel like Dangab, Bullan, Gongo, Dora Jalla, Wagdi, Gasangasa, Dangur, Guba, Wombera and the surrounding areas (Ibid). Earlier Christian raids to Gojjam and adjacent territories may probably pushed some Shinasha groups into their present localities even prior to the $16^{\text {th }}$ century. On top of this, Oromo settlement in the South of the Abbey moved other Shinasha population to Gojjam to take refuge and these enriched the Shinasha community living in the North of that river in Metekel. It should be noted that most Shinasha were subdued and assimilated into the Agaw, Amharic and Oromo speaking people. Though those who moved in to Metekel by escaping wars and military expeditions from various directions kept their language and cultural traits (Ibid).

\section{The Oromo People}

Other peoples of the area and of course, the subject of this discussion are the Oromo. 
Abebe Ano Alula

According to the accounts of Tsega, Oromo's presence in Metekel dated back to the $18^{\text {th }}$ century. These were two major routes for Oromo expansion into Metekel region. The first was the eastern route that started from the present day Limmu and Hibantu areas in Wollega to Dangab and Debati parts. The second was the western route that started from western district of Wollega and targeted Wombera. They moved to Metekel from south of the Abbey River connected to their general expansion process. The earliest movements to the area were related to the general feelings of adventure among the youth. Youth members of the society continued the ancient custom of hunting, big games and killing which brought them honor in their society and specially admiration among the women. Such temporary visits gradually led to permanent settlements in the area (Ibid).

The Oromo that settled in Wombera moved from the districts of Gidami, Bojji, Mendi and Nejjo of western Wollega. Traditions collected by Tsega reveal that a group of sixty warriors locally called Gachana Jattama headed to Wombera under the leadership of Abba Dula Aancha. After visiting the area, this group returned home and said to have reported the prosperity of the area in natural resources and suitability for settlement. Consequently, a more strong campaign in which various Oromo clans like the Amuma, Arojji, Babbo, Gidda, Iggu, Manasibu and others participated; was orchestrated under Abba Dula Jillo Wubi. This group was able to overrun the weak resistance of the early inhabitants of the Gumz and the Shinasha. Even though some Shinasha clan like the Anifo tried to protect their land, but they were routed and many of them were taken to Wollega where they were assimilated into the Oromo society. This fact opened the way for large scale movement and settlement of Oromo society in Wombera. Earlier settlers attracted more of their relatives and that escalated their number. Inter-clan conflict on land or on other cases, violent crimes as disappointment at their high status was among the factors that contributed for the movement in to and settlement in Wombera (Ibid).

\section{The Luba Basa Institution: The Challenge on Shinasha Identity?}

Right from the beginning of their expansion the Oromo had at their disposal various institution and mechanisms of establishing relationships with the people they conquered. One among such institution by which the Oromo assimilated, incorporated and subdued peoples into their society was called the Luba Basa (setting free)
Sci. Technol. Arts Res. J., April-June 2012, 1(2):101-107

institution. It was this incorporation Process or mechanism applied in Wombera to the Shinasha. The word Luba denotes freed, circumcised where as Basa means to set or to make and hence; Luba Basa can be translated as to set free or to make free (Ibid). According to Asmarom Legesse, Luba expressed as one of the five classes of Gada system, and thus at this stage (class), one could perform a large massive conquest of the new territory (Asmarom, 1973). But according to one observer, this institution is of two types. The first represents the mechanism by which the Oromo freed their captive slaves, gave them land and constructed houses for them. Freed slaves were also allowed to marry. This was applied largely to the Nilotic peoples, the Gumz mainly with an objective to use them as warriors in persistent campaigns (Tsega, 1997). The second and most widely known spread type of Luba Basa was the Medhicha.

Medhicha is a piece of a skin freshly cut off from their ribs of the animal [s] slaughtered during the adoption ceremony. A stripe of the skin is tied on the wrists of the representatives of the adopted clan members as a symbol for their complete assimilation (Ibid).

This same institution is variously described in the literature as Mogassa (Mohammed, 1990) and Gudifacha (Ibid). As to how and why the Oromo devised and evolve this institution remained controversial. Mohammad Hassen, tracing its emergence back to Buffole Gada (1546-1554) argues that it was one of the strategies devised for the sake of administration the subject peoples. He categorizes Oromo attacks into new territories in three phases. The initial phase was marked by a surprise attacks conducted usually during the night times. In addition to yielding spoils, the attacks resulted in weakening and eroding the power of the enemy. The second phase was characterized by attacks on particular weak spot of the enemy. Thus, the inhabitants had two options: either to quit or submit. It was after these repeated attacks that the Oromo moved into new territories and conquer. If the people opted to remain in their localities, they would be incorporated into the Oromo society and added to the fighting force. The third phase was characterized by the use of the newly conquered territories as abase for further attacks. Thus, it 'requires administrative innovation because now people had to be governed and not just plundered, if the home base were to be secured'. Assimilating the subdued peoples through adoption (Luba Basa) was, therefore, one of the strategies of administration ( $/ \mathrm{bid})$. Tsega states the following in connection with the reasons for the emergence of the Luba Basa institution. 
Abebe Ano Alula

In Oromo society, the non-Oromo groups were considered as "castes" and despised until they were assimilated through the Luba Basa institution. They were considered as unequal to the Oromo till they were freed or set free. Therefore, the Oromo seem to have developed the Luba Basa institutions to set them free and make them of equals themselves .It means not only the liberation of the captive slaves was as it most commonly known, but also the liberation and freeing of "caste groups" (Tsega, 1997).

The above statement can be refuted on three points. Firstly, the very existence of the 'caste groups' like the tumtu [Smith] in the Oromo society itself made the assertion less palatable. So the paradox is that, a society who had despised groups within itself established institution to 'liberate and equalize' other caste groups, the 'non-Oromo groups'. If Tsega considers the tumtu [Smith] as non-Oromo, they must have elevated to the level of equality to the Oromo right from their assimilation via the institution. But this did not happen. Secondly, the Oromo did not apply the Luba Basa especially the Medhicha, to all the non-Oromo groups that they conquered. As Tesema asserts Oromo assimilation of other groups in western Wollega was limited to the Omotic groups with the exclusion of Nilo-Saharan pastoralists who on the contrary were furiously fought and pushed back to the dry-hot, lowland basins and into the hearts of inaccessible forest (Tessema, 1997). Tsega also notes the different approaches devised by the Oromo in their relation to the Gumz. ${ }^{30}$ Thus, an institution set up to eliminate the gap between the despised 'non-Oromo group' and the 'noble Oromo' never discriminate against the Gumz. Thirdly, the degree of equality of the assimilated group and the Oromo is also questionable, as we shall see it later on. Referring to Merid, Triulzi indicates that.

$\ldots$ at the beginning the advancing Oromo treated the conquered peoples according to the 'political culture' which is said to have prevailed in the region i.e. they made them slaves and called them Gabaro... because of their mobility and because the Oromo lacked the fully developed machinery for policing large number of such people' they soon found out that 'to have resentful subject was unnecessary and potentially dangerous,' they thus restored to a system which allowed them to assimilate their new subjects and yet did not endanger their supremacy. In this way the Gabaro were attached to each clan by the bonds of which they were taken prisoners', and given age-sets so that they could regulate their own affairs (Alessandro, 1996).
Sci. Technol. Arts Res. J., April-June 2012, 1(2):101-107

Whether this adoption was inherent to the Oromo and part and parcel of their attack as Mohammed claim; or a latter phenomenon developed because of their difficulty in the courses of expansion as other argue, left open for speculation. However, their appellation for the conquered peoples and their early relations with them made the latter argument convincible. Mohammed writes that.

...The Oromo term for the conquered people was gabbaro ("those who serve"). The Oromo adopted the gabbaro en mass, giving them class genealogy, marrying their women and taking their young in the service for herding. Simultaneously, Adult men were recruited for military services in times of war and worked on the land in times of peace (Mohammed, 1980).

In a similar way, to the Oromo that maintained the upper hand over earlier settlers elsewhere; those who moved to Wombera assimilated and incorporated the Shinasha people into their society through the Luba Basa institution. This institution had its own ceremonies and symbolical rituals. However, this differs from place to place. In the case of Wombera, at the ceremony, Bulls were slaughtered, local food and drinks were served. The symbolic ritual used to assimilate was:

.... To put a yoke on the neck of the group to be adopted. The yoke was prepared from a plant called in Oromo kello. The group to be adopted broke the yoke which symbolized that their old ethnic identify was broken and that they were assuming a new one sanctioned by the following solemn Oath:

Yoo isin ganne dhallii keeya akka: if we abandon you let our descendants

Qambbarri kana hacabu: be broken (destroyed) like this yoke (Tsega 1997).

This Oath indicates their determination to completely become Oromo. They also pledged to abandon their former identify and culture. This was followed by a ritual ceremony in which the two representatives: the Oromo and the Shinasha make cuts on their respective thighs, take drops of the issuing blood and mix the blood that symbolized the newly established unity. The adopted Shinasha assumed the clan name of the Oromo adopting them. For example, those Shinasha group adopted by the Gidda clan would became Gidda, those by the Babbo clan became Babbo and soon. On the basis of this, two Shinasha brothers could be made to belong to different clans according to the clan adopting them. It should not be forgotten that these 
adoption processes were conducted in the presence of Abba Boku, who confirmed it. Intermarriage was also allowed hence forward, and most of the Shinasha of wombera were thoroughly assimilated through such marriages (lbid)

Oromo Scholars asserted that adoption of nonOromo peoples was made on the bases of their willingness and the adopted groups assumed equal position to the Oromo. In this regard, Tsega states that Luba Basa (Medhicha) was entirely based on the willingness of the clan to be adopted (lbid). Tessema also tells us that "the adopted groups were given exactly the same privilege as the Oromo..., becoming free and equal to the "Borena" Oromo" (Tesema, 1980) who had the right to lead Gada practices.

Despite what was said, it is important to question the degree of willingness and equality of the adopted groups to the so-called 'Borena' Oromo. To Begin with the nature of the arrangement itself (adoption), it was made between victor and the vanquished. Such arrangement usually goes along with the interest, willingness and in favor of the victor rather than the victim who hand presumably no option rather than accepting it. In addition to this, Tsega elsewhere describes the pressure on the nonOromo communities particularly the Shinasha in our case to accept adoption. According to him, the Shinasha were vulnerable to various attacks and despised in their economic, social and cultural life till they would accept the Luba Basa institution. They cannot sell their product in markets dominates by the Oromo and had little access to fertile lands and other resources. (Tsega, 2008). Having such things, therefore, it is difficult to conclude that adoption was entirely based on the willingness of the groups to be adopted. As to the status of the adopted groups, Triulzi writes that "(they were) regarded as the sons and equals of the 'true Oromo' in the social and ritual, but not in the ritual respect... they were assigned" the same status as that scribed drop-outs from the Gada system... ritually degraded Oromo and ritually up-graded outsides" (Triulzi, 1996). This shows that the ritual superiority of the Oromo vis-à-vis the adopted non-Oromo.

The Luba Basa institution had tremendous effect particularly on the adopted groups. Above all is resulted in the obliteration of original memory of ethnic separation within the adopted groups who were now given new genealogies and started counting their putative ancestors, in the same way as their adoptive kinsmen. 'It also cancelled all previous ties the new adoptee had with their own original group:... even that of the defeat. This is why as Oljira asserts, it becomes very difficult to differentiate the Shinasha of Horro-Gudru from the local Oromo and above all the Shinasha cannot trace themselves to separate decent other than the Oromo (Olijira, 1997).

The effect of Luba Basa on the Shinasha of Wombera is not intense as on the Sinicho/Shinasha of Horro Gudru. The Shinasha of Wombera did not yet completely forget their original ancestors. This is probably due to the proximity of the time when Luba Basa was conducted. Nevertheless, one can easily notice its effect. For instance, almost all of them can't speak the Shinasha language. They ceased to practice Shinasha culture and religious practices such as funeral culture, Sheero and Merawo. They speak Oromo language and practice largely Oromo culture.

According to my informants, Sheero mean in Shinasha funeral cultural practices, it is a kind of a fithat ceremony up on the death of someone, which as it is believed, allows the soul to enter paradise after wickedness is removed through the Fithat. It is also believed that the deceased will be cleansed and the relatives of the deceased will be in peace. In other words, it is believed that if Sheero is not conducted relatives and clan members of the deceased could be handicapped or disabled or will be subjected to calamities, and the deceased will not be in position to enter paradise. Furthermore, the same informants asserted that, Merawo is also sacrifice making ceremony performed by respected and wise elders of Shinasha in wombera. They believed that Merawo keeps the practitioners from serious disasters in the family (lbid). However; my informants make clear that, Merawo is practiced only among the Shinasha of Wombera, not in Bullen. Thus, the Shinasha of wombera represents culturally Oromo, but tracing themselves to a separate ancestor. This shows that they are on the way to completely change their identity from being Shinasha to an Oromo.

\section{CONCLUSIONS}

Thus, the Shinasha adopted and completely assimilated Oromo value, concepts, religion, language and identity. They called themselves after the Oromo clan who adapted them. They pledged an oath to the Oromo not to abandon them and to break their Shinasha identity using various symbolic rituals. Likewise, the Shinasha of Wombera adopted and completely assimilated 
Abebe Ano Alula

Oromo value concepts, religion, language and identity. They called them serves often the Oromo clan who adopted them. They ceased to practice their culture such as the funeral culture, Sheero, Merawo and the like. But one should notes that the Shinasha of Wombera did not yet forget memories of their ethnic separation probably because of the proximity of the time when they underwent through the institution.

\section{ACKNOWLEDGEMENTS}

I would like to express my heartfelt gratitude to my supervisor, Dr. Tefera Ambago, whose persistent supervision, guidance and constructive criticism had been most valuable to me.

\section{REFERENCES}

Ali Suleiman Etal. (1991). Kendil, Volume No.1, Assosa Education and Cultural Bureau.

Asmarom Legasse. (1973). Gada: Three Approaches in Study of African Society.

Beckingham, C.F., Huntingford, G.W.B. (1986). Some Records of Ethiopia, 1593-1646.

Debela Alemu. (2000). A History of Dabra-Zayt Town from Its Foundation to 1991, Wombera Senior Essay. Department Of History, Ababa University.

Fleming, C. Harold. (1976). Kaffa (Gonga) Languages. In: Non-Semitic Languages of Ethiopia. Lionel Bender, M. (ed.). Michigan State University.

Haberland Eike and Starube Helmut (1979). Nordost Afrika.Die Volker Afrikas Und Ihre Traditionellen Kulturen Hermann Baumann, (ed.), Ost-West-Und Nordafika, Teil. II Wiesbaden.

Mohammed Hassen (1990). The Oromo of Ethiopia A History 1570-1860. Cambridge University, Cambridge.

Oljira Jujuba (1994). Oromo-Amhara Relation In Hurro-Gudru Awraja (North Eastern Wollega) 1840, S-1941, M.A. Thesis. Department Of History, Addis Ababa University.

Taddes Tamarat. (1982). Early Trends of Feudal Super Imposition On The Gumz Society in Western Gojjam. An Unpublished Paper Presented in the ternational Symposium on History and Ethnography Studies, April 25-30.

Taddes Tamarat. (1988). Nilo-Saharan Interaction with the Neighboring Highlands. The Case of the Gumz of Gojjam and Wollega. In: Proceeding of Famine Experience and Resettlement in Ethiopia.
Sci. Technol. Arts Res. J., April-June 2012, 1(2):101-107

Tessema Ta'a (1980). The Oromo of Wollega: A History. M.A. Thesis. Department of History, Addis Ababa University.

Triulzi Alessandro United., Divided Borana., Gabaro (1996). Among The Macha Oromo in Western Ethiopia in Being and Becoming Oromo Historical and Anthropological Enquiries (Eds, P.T.W., Baxter Et) Uppsala.

Tsega Endalew. (2008). Luba Basa And Hrma Hodha. Traditional Mechanisms of Confict Resolution in Metekel. Ethiopia. Http: //www. Googlle. (Retrieved On Dec.30, 2008) Com.Et/Search?Q=Endalew=TsegaandL $r=A$ And Safe $=$ Off And Start $=50$ and $\mathrm{Sa}=\mathrm{N}$.

Tsega Endalew. (1997). The Oromo of Wombera. A Historical Survey to 1941. M.A Thesis. Department of History, Addis Ababa University. 